\title{
The Educational Ideology of Han Ying Dong-xue QIAO
}

\author{
China Jiliang University, Zhejiang, China
}

\author{
Keywords: Moral Education; Han Ying; Human Nature.
}

\begin{abstract}
The study on the ideology of Han Ying, a famous scribe of the Western Han Dynasty, has always been easy to ignore in the academic world. In recent years, scholars have increased their research on Korean infants, but they are still not systematic. Especially in the educational thinking of Korean infants, it is basically a blank space. He has many reasonable factors in the role of education, the principles and methods of moral education, the significance and process of learning, and family education. There are still reference values and learning values. This article is based on the overall thinking of the Korean and the infants, and focuses on the commentary on his education and moral education thoughts that are full of the characteristics of the era. He hopes to enrich and deepen the ideological research on Korean infants.
\end{abstract}

\section{Introduction}

Han Ying is a famous Confucian thinker and classical educator who was active in Yanzhao in the early Han Dynasty. He was a doctor at the time of Emperor Hanwen and served as a Master of Changshan at the time of Emperor Jingdi. The activities of Han Ying's life mainly consisted of book writing and teaching students and students. He learned Hongbo and is proficient in the Book of Songs and is also a long book of the I Ching. Yan Zhao's study of the Book of Songs is mostly based on Han. The educational activities of Korean infants are very influential. Hundreds of years in the late Eastern Han Dynasty, Han learning has always been the court's attention, "Han poetry" is listed as one of the teaching subjects of Tai Xue, is also a subject of many Hong Xue masters.

Han Ying's books include "Han Shi," "Han Gu" 36 volumes, "Han Nei Zhuan" 4 volumes, "Han Wai Zhuan" 6 volumes and so on. One of the most famous is his "Han Shi Whai Zhuan," which explains the interpretation of Confucianism and the summarization of pre-religious thoughts. There is also no shortage of play on Confucianism. It is an important study of pre-Qin literature, Confucianism and Confucian education in the two Han dynasties. The educational thought of Han Ying is mainly embodied in this book.

\section{Human Nature and Education}

Regarding the relationship between human nature and education, Han ying put forward the following arguments: "If the sexuality is silk, if a woman's work is inflamed, if she pulls out her control, she will not become a silk. Fu Fuyu will not become a young when he accumulates a long day. If the wife is good, she must be able to support the king's lord and help him. If he is inside, he will not be a gentleman." "The habits of the husband and the scholar are slightly different, deep and solid, and smooth. In the bones and bones, Zhen $\mathrm{Yu}$ is a painter. He is also a gentleman." It is not difficult to see that Korean infants attach great importance to the role of acquired education and individual subjective initiative. Only after the "Sage King helps to carry" and "inside the Tao" can it become a "gentleman". Therefore, the acquired "cultivation" is the only person. On the one hand, it advocates that man has an inherent "good heart" and on the other hand, he regards the acquired learning as very important. This shows that he has accepted the different humanistic views of Meng and Yu. To say that the theory of good nature carries a transcendent idealism color, then the acquired "learning" and "inside by virtue" are materialistic viewpoints. This seems to be worthy of recognition today. 


\subsection{Pay attention to education}

Through the interpretation of The Book of Songs, Han Ying made a ruthless critique of the tyranny of the Qin Dynasty. He believes that the main reason for the Qin Dynasty's rapid death is "behavior, righteousness and wrongness." Therefore, he inherited Mencius's thinking and stressed that righteousness and ritual should be used to govern. The important role played by the country is to use education to eliminate bad faith and stabilize the society. He pointed out: "The priests are very critical in governing and arguing, and the strength of the country is also the same as the prestige, and also the fame of the fame. Therefore, even if one day does not, it is not for the sake of the community." He used rituals and teacher teachings as methods of conditioning and maintaining true minds. He also quoted the praise of Zhou Wenwang in The Book of Songs. The reasons why the king of Zhou Wenwang was inspired were: "Righteousness and Punishment, Literacy, Faithfulness and Communication".

Han Ying regards basic material living security as a necessary condition for education, which is consistent with Guan Yu's "warehouse inspection, knowledge and honor" and Confucius's "rich and taught" view. He said: "The hunger and thirst of bitterness and irritability, and the cold and the hot summer moving the skin, these four, the people of the great harm. The big harm does not eliminate, can not teach Yu also. Four bodies do not hide, then fresh benevolent people, five Tibetan emptiness, then No scribes, so first the king of the law, the pro-Tianzi pro-treading, after the cricket pro-silkworm, the world first yi clothing and food also; "said:" husband people no lack of food, outside without suffering from cold, you can teach the imperial eunuchs. He also said: "Building a city and staying in it, do not raise the field and teach it through education." The educational conception of Korean infants is closely related to the theories of good nature and health. The theory of good nature provides the basis for the education of the people. The theory of health care puts the relief of the lives of the people in an important position. Therefore, it has the ideas of being able to raise and then teach. This is a matter of course.

In order to implement education more effectively, Korean infants require courtesy to be concise and practical. He said: "Morality is not known, people cannot help; He advocated the establishment of a school and adopted the form of a top-down, capital, and Quartet form to enlighten the people.

Han Ying not only promoted "politicians" and "courtesy education", but also absorbed Xunzi's idea of "promoting courtesy and courtesy." He praised "french religion" and used rituals and punishments. He said, "If the material is counter-timed, it will be dead, that is, it will be heaven." He called the person who executed violating the decree to be called the Heavenly Strangulation. The educational concept of Korean infants is to serve the maintenance of feudal rule. Although there is also a side that embodies the people's nature, the main purpose is to "fudge to the king" and make the landlord class more stable.

\subsection{Principles and methods of moral education}

Han Ying said: "I do not know the life, do not think gentleman," "I do not know why it is heaven, but also won the gentleman call?". It can be seen that "knowing the fate" and "Tiantian" are the primary principles of his moral education. He believes that human beings are born with the "righteousness, wisdom, and virtue of goodness." If you don't know what God uses to give you life, you can't have a "good heart," and you can't be a gentleman. "That is heaven" means to follow the heavens, maintain their inherent goodness, and follow the social etiquette, because "the priests are the bodies of the heavens and the earth, and the verses of the people are their own verses". "Knowing the fate" and "Tiantian" mean that people should consciously abide by the feudal morals. "By the way, it is fair and unselfish, it is not for the sake of peace, and it is not for the danger." In fact, he put these two People see it as the basic requirement for dealing with the relationship between people and between people and society.

Han Ying believes that one's virtues are manifested in two aspects: one is the intrinsic moral understanding and moral conviction, and the other is the external "color tolerance", "voice", "words", and "things". Moral education should begin by cultivating internal qualities and develop good psychological qualities. He regards moderate conditioning and temperance as moral 
cultivation. He believes that only by controlling the emotions of sex, emotions, emotions and emotions, and temperament to control individual cravings, can it be in accordance with the psychological laws of moral formation. .

Han Ying emphasizes the study of the sages who are "being self-possessed" and "cultivating self-denial and then governing others". It is argued that "If you teach at the first place and serve it first, then the people will be swept by the wind. If you do not follow the line, then Egypt will use the punishment, then the people will know the sin." It is believed that only the rulers can take the lead in setting standards and taking the lead in implementing state decrees, so that ordinary people can obey.

He pointed out: "Everybody who cures gas and nourishes his heart is moaned by rites, Mo Youde is a teacher, and Mo Shen is a good person. One is a good biography, the transmission is fine, the essence is God, and God is a rule also". We believe that no matter what the gentleman does, he should follow the rules of etiquette and righteousness. Han Ying emphasized that to cultivate one's morality and culture must be "one good", that is, the love of liberty must be specific, and there must be unshakeable will and morality. He advocated that the guidance of the wise men would greatly benefit the cultivation of the mind, and he believed that a good teacher not only had "a source of wisdom", but also "behaved as a watch".

\section{Teaching Ideas}

Han Ying has a long history of teaching classics and has very rich teaching experience. He has unique insights in teaching thinking.

\subsection{The significance of learning}

"Han poetry," said: “Jade doesn't work, it doesn't turn into a device. People don't learn and they don't do it... If a gentleman seeks it, he will use it for his country. Then he moves the people and the people will delay the life. In his view, learning is not only Regarding individual achievements, but also related to the rise and fall of the country, the viewpoint of Korean infants is politically far-sighted, and Han Ying also inherited and carried forward the viewpoint of Sengzi's "learning not to end even afterwards" and put forward the concept of "learning not to end", but $\mathrm{He}$ said that learning, as a process that runs through life, has the essence of lifelong education. It is very valuable.

\subsection{Learning process}

He emphasized the combination of learning, thinking, and action. He said: "If you don't learn and think well, you don't know much about it; if you study it and you don't understand it, you don't respect it." He believes that learning is effective. In the end, it should be reflected in ethical behavior. This is a point worthy of our attention. He also believes that people must have realistic and modest moralities in order to acquire real knowledge in their studies. He said: "If you can't study, you don't know where you are. Although you must know, then you must know."

\subsection{Teaching staff}

Teaching comprehension is an important principle of Confucian teaching and Korean infant teaching.

He also paid attention to the use of this principle. He said: "The sword is good, but it is not constant. Although the material is beautiful, you cannot learn it. Although there is a delicacy, you don't want to know what it is. Although there is good manner, you cannot learn from it. Therefore, they learnt that they didn't know enough, they taught it and they didn't know it. It wasn't enough, so it was self-proclaimed. It wasn't studied, so it's done with the best of the teachers. From this point of view, the teaching is also well-known." He also asked Zixia to ask questions from Confucius. Confucius discussed issues with him as an example to illustrate the need for teacher-student mutual inspiration and mutual promotion. He believes that such masters as Confucius can still be inspired by students' questions, and ordinary teachers will receive more 
benefits.

\section{Summary}

In "The Story of Korean Poetry", Han Ying repeatedly discussed the issue of family education. The story of the unfamiliar father and the mother of Tian $\mathrm{Mu}$ is a clean and honest story. He praised Meng Xi and Tian Ji's mother, "The Good Mother makes the Son Yin Xian." It was their attention to the children's education and influence that they cultivated famous scholars and politicians. Han Ying also saw that his father played a non-negligible role in his child's growth. He clearly stated that he should be a husband. He said: "If husband is a father, he will love the benevolent love to raise his son and follow his diet. All his body, and his knowledge, he must be strict and righteous, with the lead in it, and his hair is also sent to teach the teacher to become its technology. Nineteen see records, please Guanbinzhi, enough to become its own virtue. Jing, the appointment of the inside of the set, believe in the pro-grant, no doubt. The crown is not ambiguous, the child does not answer, this is the father of the road also." In his view, the father of the child should have kindness and care Feelings, we must pay attention to the impact of the environment and education on children, strict with self-discipline, and guide children to follow the correct path; do not whip children in childhood, do not scold adult children, and fully trust them. The fatherly path advocated by Han Ying is based on the laws of children's physical and mental development, making full use of the positive factors in the environment and nurturing the child into a highly skilled and noble person. This emphasis on the role of fathers in family education and the idea of fully respecting children's individuality is a breakthrough in the theory of family education at that time. It still appears to be an important part of family education today.

\section{References}

[1] Han Ying. Han Shu Rulin Biography [M].

[2] Han Ying. Han Shi Wai Zhuan [M]. Volume 5, Chapter 17.

[3] Han Ying. Han Shi Wai Zhuan [M]. Volume IV, Chapter 26.

[4] Han Ying. Han Shi Wai Zhuan [M]. Volume 2, Chapter 31.

[5] Han Ying. Han Shi Wai Zhuan [M]. Volume V. Chapter Thirty-two.

[6] Han Ying. Han Shi Wai Zhuan [M]. Volume 3, Chapter 38.

[7] Han Ying. Han Shi Wai Zhuan [M]. Volume 3, Chapter 20.

[8] Han Ying. Han Shi Wai Zhuan [M]. Volume IV, Chapter X.

[9] Han Ying. Han Shi Wai Zhuan [M]. Volume II, Chapter 31.

[10] Han Ying. Han Shi Wai Zhuan [M]. Volume 3, Chapter 38.

[11] Han Ying. Han Shi Wai Zhuan [M]. Volume 5, Chapter 23.

[12] Han Ying. Han Shi Wai Zhuan [M]. Volume 5, Chapter 9.

[13] Han Ying. Han Shi Wai Zhuan [M]. Volume 7, Chapter 2.

[14] Han Ying. Han Shi Wai Zhuan [M]. Volume 3, Chapter 22.

[15] Han Ying. Han Shi Wai Zhuan [M]. Volume 2, Chapter 31.

[16] Han Ying. Han Shi Wai Zhuan [M]. Volume II, Chapter Thirty-two.

[17] Xun Zi. Xunzi • Encouragement [M].

[18] Han Ying. Han Shi Wai Zhuan [M]. Volume 8, Chapter 23. 
[19] Han Ying. Han Shi Wai Zhuan [M]. Volume 6, Chapter 9.

[20] Han Ying. Han Shi Wai Zhuan [M]. Volume VI, Chapter 7. 